\title{
TMEM121 Protein Is a RegulatIon Factor in the Proliferation Activity of the Adrenocortical stem/Progenitor Cells
}

\author{
Mohammed Abdalmalek Ali Al-Bedhawi \\ Scholar researcher, Institute of Genetic Engineering and Biotechnology, University of Baghdad, Iraq
}

\begin{abstract}
Several studies have identified adrenocortical sub-population cells located in the capsule/sub-capsular area, carrying the aspects of stem/progenitor cells. We previously recognized a novel protein (Tmem121) highly expressed in in this sub capsular area and also highly co-localised with Ki67 in this area. The suggestion of these previous studies was considered to clone and transfect Tmem121 into adrenocortical stem/ progenitor cells studying the proliferation changes in the transfected cells. Adrenocortical stem/progenitor cells were isolated and cultivated in vitro. The cells were previously isolated and prepared for testing the effect of Tmem121 after three months of in vitro cultivation. Specific primers were used to detect and amplified the coding sequence of the TMEM121 using RT-PCR followed by cloning into pIRES2-ERFP vector. Immunocytofluorescent tests were carried out to detect the forced expression of TMEM121 into these cells. Real time PCR assays were followed with specific primers to detect the synchronization of Tmem121 expression with two proliferation markers Ki67 and proliferating cell nuclear antigen (PCNA). Immunocytofluorescent tests results showed a significant expression of TMEM121 into these cells. Real time PCR results showed a significant increase in the expression of both proliferation markers Ki67 and (PCNA). These results suggested a propagating effect of TMEM121 to the adrenocortical stem/progenitor cells.
\end{abstract}

Keywords: Tmem121, proliferation, adrenocortical stem/progenitor cells, PCNA and Ki67.

\section{Introduction}

Adrenal cortex have been suggested to have a clusters of undifferentiated cells in the capsule and sub-capsular area with limited steroidogenic capacity in mice $^{(1)}$ and humans ${ }^{(2)}$. These cells have shown a relatively high proliferating activity and suggested to represent the stem/progenitors cells that responsible of replenish the adrenal cortex ${ }^{(3)}$. More recent studies also suggested these cells occupied the capsule and the subcapsular areas as a stem/progenitor neich ${ }^{(4-6)}$.

Although Tmem121 was a poorly studied protein, recent findings regarding its role have been developed. Tmem121 is a member of a family are highly expressed in most embryonic tissues ${ }^{(7)}$. A wound healing study showed that Tmem 121 is one of the genes that contribute to cell proliferation and migration in human endothelial cells ${ }^{(8)}$. However a recent study forced its expression into MDA cell line but showed no significant effect on the proliferation activity of these cancer cells (un-puplished data). A histological study showed high expression of Tmem121 in capsule and sub-capsular areas of the adrenal cortex with relatively high co-expression of Tmem121 with Ki67 on the adrenal sections ${ }^{(9)}$. These finding suggested study the effect of cloning and transfection of Tmem121 in more specific cells as adrenocortical stem/progenitor cells to investigate its role in the proliferation activity.

\section{Materials and Method}

Experiments that conducted in this study were in agreement with all the guidelines and regulations of the committee on experiments of the school of biomedical sciences, University of Reading, UK.

Animals: Adrenal glands used in this study were freshly isolated from adult Wistar-rats (weight 250$350 \mathrm{~g}$ ) from Harlan Envigo UK were housed in rooms where the ambient temperature and light were under automatic control. The rats were treated under the United Kingdom Home Office Animals Act 1986. Rats were euthanised by $\mathrm{CO}_{2}$ asphyxiation. 
RNA isolation, cDNA synthesis and RT-PCR: TRIzol reagent (Ambion) was used for the isolation of RNA from rat adrenals following the protocol previously described ${ }^{(10)}$. For synthesis of total cDNA, a RevertAid First Strand cDNA synthesis kit was used. PCR was used to detect the expression of the Tmem121, as well as amplifying its full coding sequence. PCR was used to target transcript variant $\mathrm{X} 1$, mRNA (accession number is XM_006225896.3) using specific pair of primers. These primers were designed with NCBI primer design tool. The reaction mixture of PCR included $25 \mu$ of $2 \mathrm{x}$ master mix of Extensor Hi-Fidelity PCR which mixed with, $1 \mu \mathrm{l}$ of $(10 \mu \mathrm{M})$ Forward primer $5^{\prime}-3^{\prime}$ GCAGGACCTCGTCCCGCTTT That positioned in the sequence (194-217) and $1 \mu$ of $(10 \mu \mathrm{M})$ Reverse primer 5'-3` TAGTCCAGCGTCTGTGCGGC that positioned in the sequence (1252-1233)). PCR conditions for this reaction were as follows: $94^{\circ} \mathrm{C}$ for 1 minute for the initial denaturation and, followed by 36 cycles of $94^{\circ} \mathrm{C}$ for 20 seconds for denaturation, $59^{\circ} \mathrm{C}$ for 20 seconds for primer annealing, finally the extension at $72^{\circ} \mathrm{C}$ for 3 minutes. After cycling, PCR products were separated by electrophoresis on a $1 \%(\mathrm{w} / \mathrm{v})$ agaros gel with $1 \mathrm{~kb}$ plus ladder (generuler). The targeted bands were excised and the DNA purified from the gel using QIAquick Gel Extraction Kit (Qiagen).

Tmem121 gene cloning: The amplified segment of the Tmem121 was applied to the next PCR to add the restriction sites that required for cloning. Primers for this PCR were new and designed to have the same sequences in addition to restriction site sequence and CGC or GCG platform up-stream the primers. The two restriction sites of the two primers were chosen carefully to set the gene of interest correctly in the vector (pIRES2-ERFP is a modified version of the pIRES2-ERFP) and not cut through the gene sequence. The EcoR1restriction sequence (5'-GAATTC-3') was added upstream the Tmem121 forward primer and the HindIII restriction sequence 5'-AAGCTT-3'was added upstream thereverse primer. Primer sequences for cloning Tmem121 gene into pIRES2 ERFP vector were: EcoR1-forward primer (5) GCGGAATTCGCAGGACCTCGTCCCGCTTT

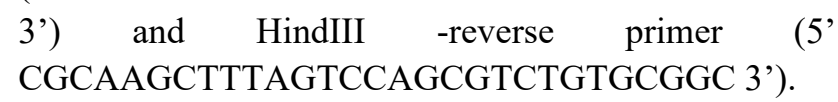

The components of the cloning PCR reaction were mixed as described previously using the PCR product of the first PCR as DNA template. The targeted band of the Tmem121 was excised and the DNA purified.
Digestion, ligation and transformation of competent cells: Both the plasmid and insert were digested with the two restriction enzymes (Promega), The components were assembled in a total volume of $20 \mu 1$ using $2 \mu 1$ of $10 \mathrm{x} 10 \mathrm{X}$ MULTI-CORE ${ }^{\mathrm{TM}}$ Buffer (Promega), The reactions were mixed and then incubated for $2-4$ hours at $37^{\circ} \mathrm{C}$ in a water bath. The digested DNA was profiled by agarose gel electrophoresis. The targeted bands of the digested vector and the digested gene of interest were excised and purified. Ligation reactions were carried out using T4 ligase (Promega) to ligate the gene of interest to the pIRES2-ERFP vector. This addition of the DNA insert and vector was conducted using a 3:1 (insert: vector DNA) molar ratio. The reactions were mixed and incubated overnight at $4{ }^{\circ} \mathrm{C}$. Ultra Competent" cell (Mach1TM Escherichia coli (E. coli) were prepared.

Purification and sequencing of insert-vector complex: The blue-white screening was conducted for identifying recombinant bacteria that contained the plasmid of interest. Plasmid DNA was isolated using Midiprep purification kit according to the provider's recommendations. The purified complexes were sequenced. Ten microliters of the purified plasmid $(100 \mathrm{ng} / \mu \mathrm{l})$ were submitted to Source BioScience for sequencing in both directions using the appropriate primer sites located in pIRES2-ERFP vector.

Adrenocortical stem/progenitor cell preparation: Adrenal cortex cells were isolated following the method previously described by Al-Bedhawi, $(2018)^{(10)}$. The cells were dispersed in minimum essential media (MEM) containing $0.6 \mathrm{mg} / \mathrm{ml}$ collagenase type I (Worthington) and pancreatin (Sigma) $0.5 \mathrm{mg} / \mathrm{ml}$. After each digestion the enzymatic activity was inhibited by the addition of $10 \%$ foetal calf serum (FCS) to the medium. Cell viability was assessed using trypan blue The isolated cells were maintained in culture medium at $37^{\circ} \mathrm{C}$ in humidified atmosphere of $5 \% \mathrm{CO}_{2}$ in air. Magnetic Activated Cell Sorting (MACS) was used to isolate target cells that were expressing Thy-1 using Thy-1 antibody attached to Pierce NHS-Activated magnetic beads following the protocol from the manufacturer.

Transfection of cells with Tmem121: The transfection was carried out using ransfection reagent (TurboFect) after cloning of Tmem121 into pIRES2 ERFP vector. As well as transfection with the plasmid only without insert (native-plasmid) as controls. Cells were $70-80 \%$ confluent at the day of transfection. The 
efficiency of the transfection was examined using an inverted fluorescent microscope (Inverted Epifluorescent Microscope AXIO) to evaluate the rate of the transfection

\section{Immunocytofluorescence:}

Dual Immunocytofluorescence assays were conducted to confirm the transfection efficiency and the expression of Tmem121 pattern in the Thy-1 cells (stem/progenitor adrenocortical cells). Cells were incubated with the primary antibodies: Thy- 1 antibody, diluted to $1.5 \mu \mathrm{g} / \mathrm{ml}$ and Tmem121 1:200 dilution (ab151077) overnight at $4^{\circ} \mathrm{C}$. The cells were washed with PBS $(3 \mathrm{x})$, incubated with 546 or 647 Alexa-fluor conjugated secondary antibody at a 1:200 dilution for $30 \mathrm{~min}$ before washing with PBS (3x). The coverslips were mounted with DAPI (VECTASHIELD). In the immunocytofluorescence both primary and secondary antibodies (mouse and rabbit) were mixed together in the primary and secondary incubation steps, respectively.

Real time PCR assays: Two-step quantitative RTPCR (RT-qPCR) was employed to detect changes in the gene expression of Tmem121, and the proliferation markers Ki67 and PCNA after the transfection of Tmem121 to the target cells. Cells were collected after 2 and 4 days of transfection. The RNA was isolated from the transfected cells using RNeasy mini kit (qiagen). The isolated RNAs from the biological replicates were mixed together before conducting the cDNA synthesis. Equal RNA concentration (400ng) was used to make the first-strand cDNA. qPCR reactions were set up to analyse the gene expression as fold changes using the $\Delta \Delta \mathrm{Ct}$ method in comparative quantification. $\beta$-Actin was the housekeeping gene in this experiment. qPCR primers were designed. The details of $\mathrm{qPCR}$ primers are in (Table 1). The reaction of each well was set up as follows: $0.3 \mu \mathrm{L}$ primers mix $(5 \mu \mathrm{M})$ each, $7 \mu 1$ of $2 \mathrm{x}$ quantiTect SYBER Green PCR master mix (Qiagen) and $6.7 \mu \mathrm{l}$ of the diluted cDNA. The qPCR program was as follow: initial denaturation at $95^{\circ} \mathrm{C}$ for 15 minutes was used and then 40 cycles of $95^{\circ} \mathrm{C}$ for 15 seconds followed by $60^{\circ} \mathrm{C}$ for 1 minute. The final step was to show the melting curve of the products. qPCR was performed using a computerized AB Applied Biosystem.

Table 1: List of primers (Invitrogen) used in the RT-qPCR, their accession number, position in the mRNA sequence and their product size.

\begin{tabular}{|l|c|c|c|c|}
\hline Gene & Forward primer 5-3 & Reverse primer5'-3 & $\begin{array}{c}\text { Fragment } \\
\text { Size (bp) }\end{array}$ & Accession number \\
\hline$\beta$-Actin & CACCCGCGAGTACAACCTTC & CCCATACCCACCATCACACC & 207 & NM_031144.3 \\
\hline Tmem121 & GCCTTAGATCTGCTGGATCTGC & CCCTTGCATACTGACCTCACTG & 159 & XM_006225896.3 \\
\hline Kia67 & TTCCAGACACCAGACCATGC & ACTGGTCTTCCTGGTTGTGG & 89 & XM_006230453.2 \\
\hline PCNA & AGGACGGGGTGAAGTTTCTG & AGCAAAAGTTAGCTGAACTGGC & 134 & NM_022381.3 \\
\hline
\end{tabular}

Statistical Analysis: Results of RT-qPCR data were analysed using Dunnett's Multiple Comparison Test of one-way analysis of variance (ANOVA).

\section{Results and Discussion}

RT-PCR experiments were successfully carried out to amplify the whole coding sequence of Tmem 121 . RNA isolation from rat adrenals was achieved with concentrations ranged from $(0.8-1.2 \mu \mathrm{g})$ with high purity. Aliquots of RNA were used for cDNA synthesis followed by PCR to amplify the full coding sequence of Tmem121using specific primers. The amplified amplicon was successfully detected, excised and purified from agarose gel after electrophoresis. The purified DNA band of Tmem 121 was used as template in a second PCR using specific primers of same sequences in addition to restriction site sequence and platform up-stream the primers. The resulted PCR product was profiled on agarose gel electrophoresis, which showed a single band represents the full coding sequence of Tmem 121 flanked by the EcoR1 restriction sequence and HindIII restriction sequence to be ready for digestion with those two enzymes.

The Tmem121 insert were successfully cloned into the vector and all negative and positive controls were prepared as well and successfully applied to competent 
cells for transformation. Plasmid-insert complex was successfully detected in the transforms colonies, which was purified with midiprep kit. The purified vectors were used to transfect the adrenocortical stem/progenitor cells with transfection reagent (Turbofect). The transfection efficiency ranged from $35-60 \%$. Although, Turbofect is a strong cationic polymer efficiently used for transfection, this low-medium transfection efficiency rate (35-60\%) resulted from the refractory nature of the primary cell ${ }^{(11)}$.

Immunocytofluorescent: The results of the dual Immunocytofluorescence assays were showed the coexpression of the Tmem121 in the transfected cells
Medico-legal Update, January-March 2021, Vol. 21, No. 1

(as confirmed by the vector reporter (red fluorescent) confirming the successful transfection in the stem/ progenitor cells identified with anti-Thy-1 antibody in comparison with control cells (Figure 1).

Although Thy-1 cells in this study were used after spending three months in cultivation, they were potentially young stem/progenitor cells because they hold similar proliferation rate to these cells in their niche, which were proliferate more constantly and can survive longer in vitro ${ }^{(10)}$ in comparison to the whole adrenal primary culture which tends to lose their survival ability after 100 days in vitro ${ }^{(12)}$.

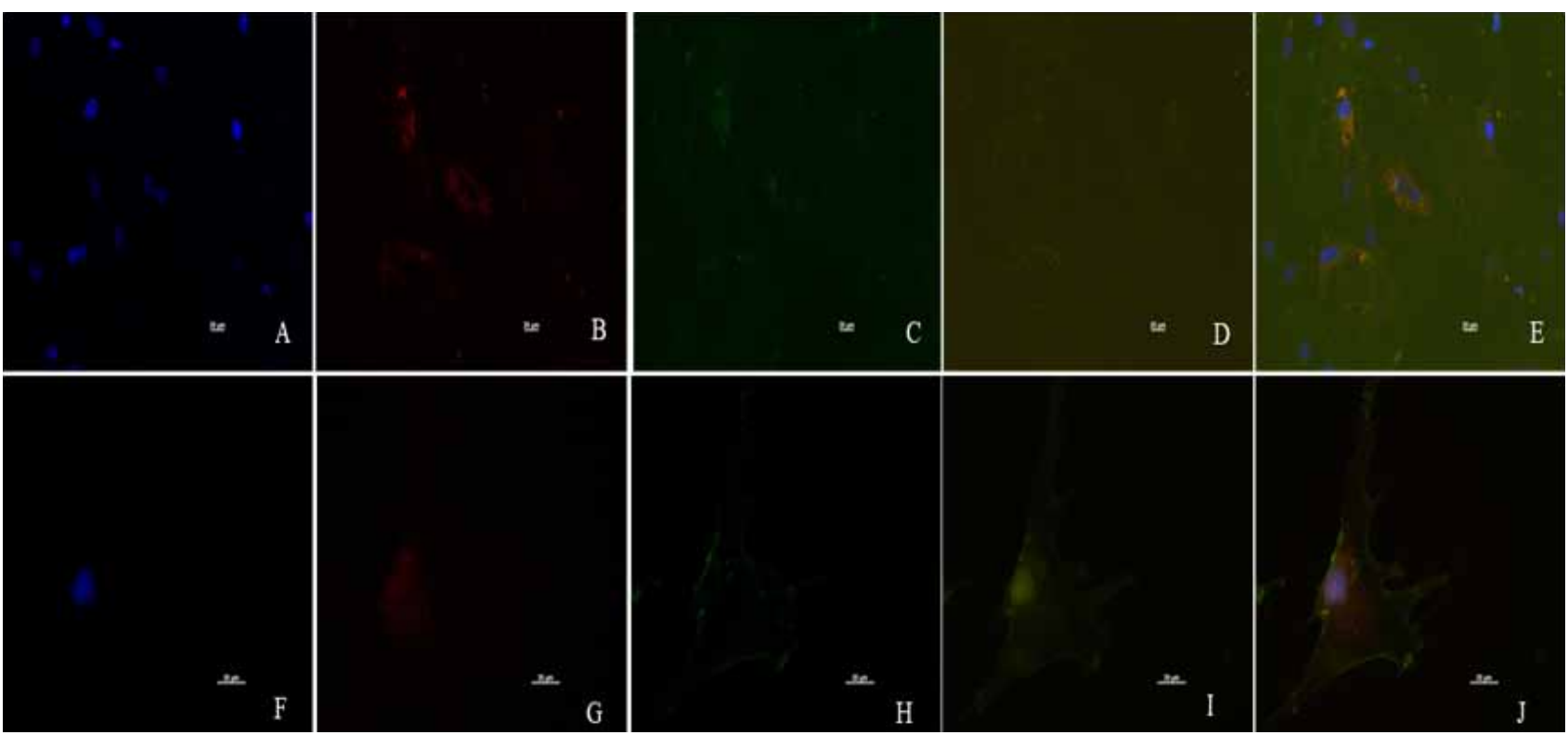

Figure 1: Dual-immunocytofluorescence on three months old cultures of stem/progenitor adrenocortical cell (Thy-1cells). Cells were transfected with native pIRES2-ERFP vector (A-E). Cells were transfected with Tmem121 gene cloned into pIRES2-ERFP vector (F-J).

Cells were fixed and incubated with primary rabbit anti-Tmem121 antibody (ab151077) before detection with secondary anti-rabbit Alexa 546 in $D$ and I. cells also were incubated with mouse anti-Thy-1 antibody before detection with secondary anti-mouse Alexa 488 in $C$ and $H$. All samples were mounted and cell nuclei were stained with DAPI in (A and F). Red fluorescent protein resulted from pIRES2-ERFP vector in B and G.

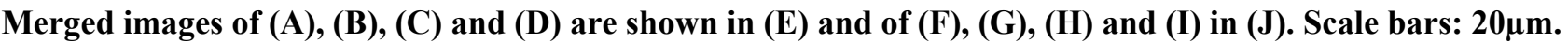

RT-qPCR: The transfection of Thy-1 cells with the coding sequence of Tmem121 gene showed significant responses in both proliferation markers $\mathrm{Ki} 67$ and PCNA as measured using two steps-Real time PCR. The control group of this assay were the cells that transfected with native-plasmid which also compared with un-transfected cells in addition to the cells received the Tmem 121 gene. The results showed a significant $(\mathrm{P}<0.05)$ and $(\mathrm{P}<0.01)$ increase in the expression of Tmem 121 two days and four days after transfection respectively (figure1). This result revealed the gradual elevation in the gene expression of Tmem121 due to the time required to SV40 promoter in vector to elevate the expression level in the host cell.

The response of both proliferation markers were also increased in synchronising with the elevation of 
the expression of Tmem121. Ki67 expression increased in harmony with the expression of Tmem121 which revealed similar significant $(\mathrm{P}<0.05)$ and $(\mathrm{P}<0.01)$ increase after two and four days of transfection respectively (figure2). Although PCNA also showed positive response to Tmem121 elevated expression, it was less than the response of Ki67. PCNA showed nonsignificant increase in the expression after two days of transfection. However, after four days of transfection PCNA showed a significant $(\mathrm{P}<0.05)$ increase in its expression (figure 2).
These results revealed a positive relationship between the expression of Tmem 121 and the proliferation activity of the adrenocortical stem/progenitor cells represented by two proliferation markers. These results were confirming the suggested relationship between Tmem121 expression in capsule and sub-capsular areas of the adrenal cortex with $\mathrm{Ki}^{\left({ }^{(9)}\right.}$.

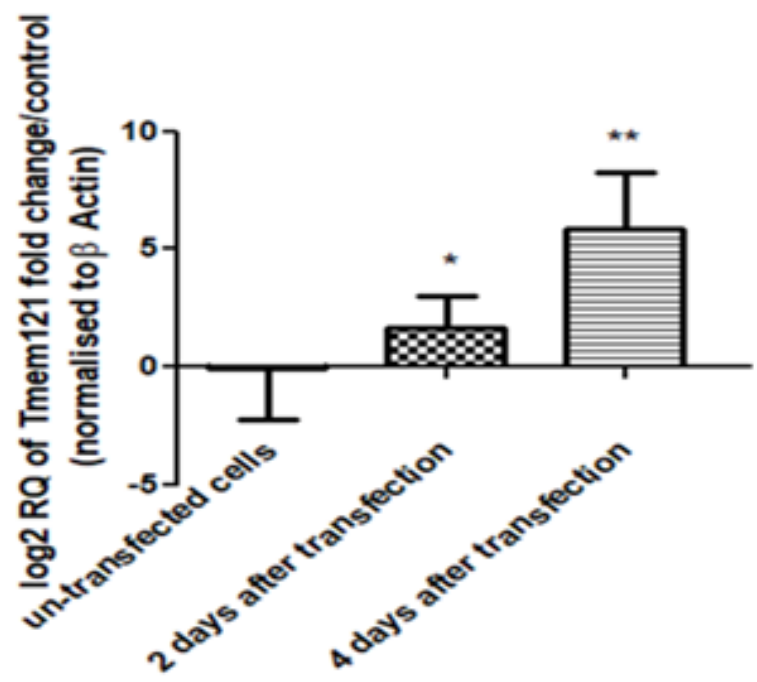

Tmem121
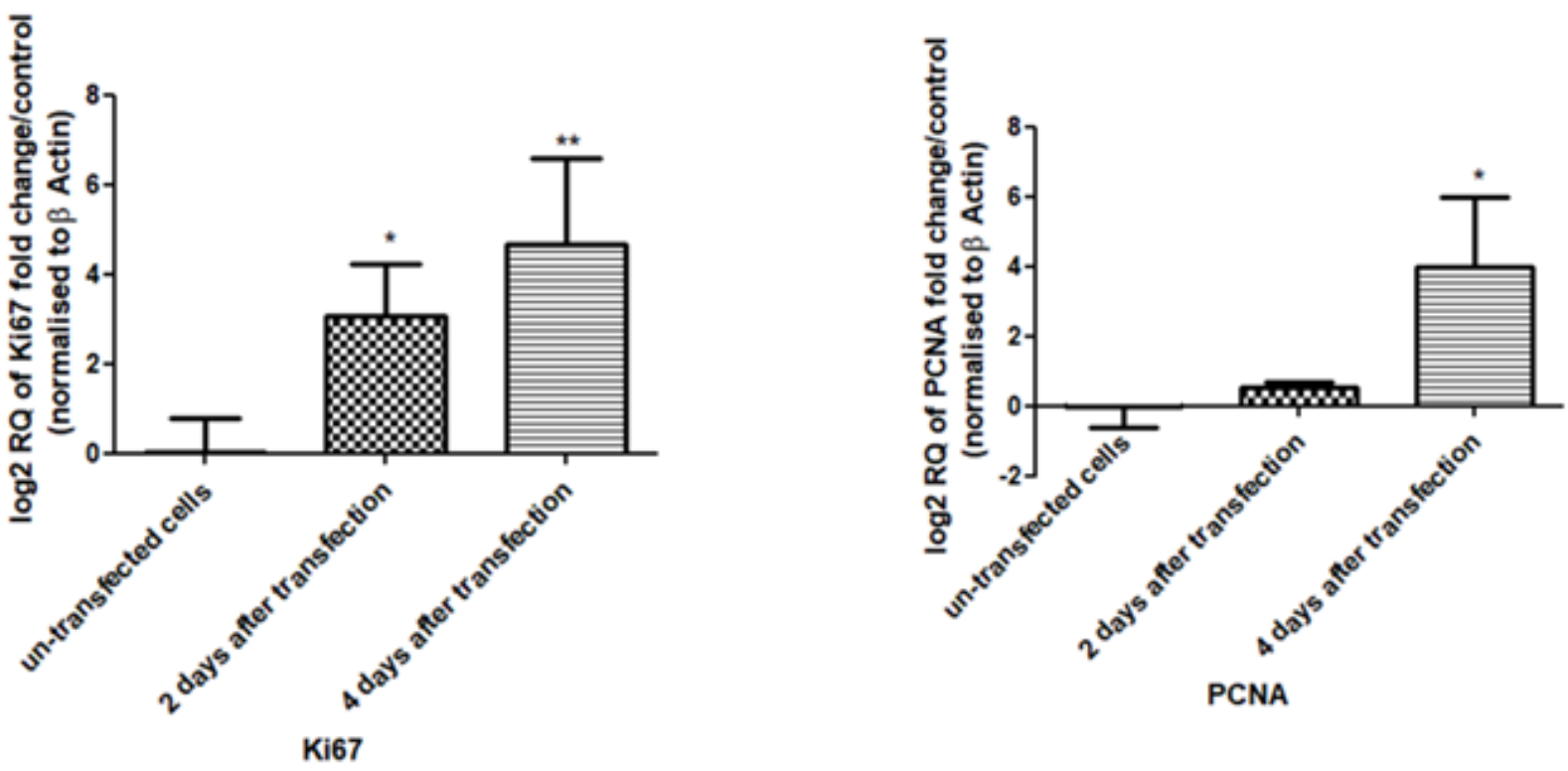

Figure 2. RT-qPCR relative quantification represented fold changes of mRNA expression of Tmem121, Ki67 and PCNA in the Thy-1 cells after Tmem121 transfection. The cells were transfected in their 3 rd month of in vitro cultivation and the gene expression was then tested at two interval periods 2 and 4 days after transfection. Three biological replicates were used in this experiment. Summarized one-way ANOVA results showed significant * $(\mathrm{P}<0.05)$ and/or significant ** $(\mathrm{P}<0.01)$ difference. 


\section{Conclusion}

Elevating the expression of Tmem121 in the adrenocortical stem/progenitor cells by cloning and transfection induce a significant increase in the proliferation markers Ki67 and PCNA. This positive incorporation of Tmem121 with these two markers suggested a propagating effect of TMEM121 to the adrenocortical stem/progenitor cells.

Acknowledgments: We would like to thank all staff and colleague at Hopkins laboratories at University of Reading for their support, training and to have the opportunity to use their labs conducting our experiments. Special thanks to Dr. Andrew Bicknell, Elizabeth Lander and Phil Dash for their support during commencing our research.

\section{Conflict of Interest: None}

Funding: Self

Ethical Clearance: Not required

\section{List of Abbreviation}

\begin{tabular}{|l|l|}
\hline DMEM & Dulbeccos Modified Eagle's Medium \\
\hline dNTP & Deoxyribose nucleoside triphosphate \\
\hline E.coli & Escherichia coli \\
\hline ERFP & Enhanced Red Fluorescent Protein \\
\hline FISH & Fluorescent In situ hybridisation \\
\hline PCNA & Proliferating cell nuclear antigen \\
\hline RT-PCR & Reverse transcription-polymerase chain reaction \\
\hline RT-qPCR & $\begin{array}{l}\text { Reverse transcription-quantitative polymerase } \\
\text { chain reaction }\end{array}$ \\
\hline Tmem121 & Transmembrane protein121 \\
\hline$\beta$-Actin & Beta-Actin \\
\hline
\end{tabular}

\section{References}

1. HEIKKILA, M., PELTOKETO, H., LEPPALUOTO, J., ILVES, M., VUOLTEENAHO, O. \& VAINIO, S. Wnt-4 deficiency alters mouse adrenal cortex function, reducing aldosterone production. Endocrinology. 2002, 143, 4358-65.

2. NISHIMOTO, K., NAKAGAWA, K., LI, D., KOSAKA, T., OYA, M., MIKAMI, S., SHIBATA, H., ITOH, H., MITANI, F., YAMAZAKI, T., OGISHIMA, T., SUEMATSU, M. \& MUKAI, $\mathrm{K}$. Adrenocortical zonation in humans under normal and pathological conditions. 2010, J Clin
Endocrinol Metab, 95, 2296-305.

3. CHANG, S. P., MORRISON, H. D., NILSSON, F., KENYON, C. J., WEST, J. D. \& MORLEY, S. D. Cell proliferation, movement and differentiation during maintenance of the adult mouse adrenal cortex. 2013, PLoS One, 8, e81865.

4. WALCZAK, E. M. \& HAMMER, G. D. Regulation of the adrenocortical stem cell niche: implications for disease. 2015, Nat Rev Endocrinol, 11, 14-28.

5. LERARIO, A. M., FINCO, I., LAPENSEE, C. \& HAMMER, G. D. Molecular Mechanisms of Stem/ Progenitor Cell Maintenance in the Adrenal Cortex. 2017, Front Endocrinol (Lausanne), 8, 52.

6. PENNY, M. K., FINCO, I. \& HAMMER, G. D. Cell signaling pathways in the adrenal cortex: Links to stem/progenitor biology and neoplasia. 2017, Mol Cell Endocrinol, 445, 42-54.

7. ZHOU, J., LI, Y., LIANG, P., YUAN, W., YE, X., ZHU, C., CHENG, Y., WANG, Y., LI, G., WU, X. \& LIU, M. A novel six-transmembrane protein hhole functions as a suppressor in MAPK signaling pathways. 2005, Biochem Biophys Res Commun, 333, 344-52.

8. BRONNEKE, S., BRUCKNER, B., SOHLE, J., SIEGNER, R., SMUDA, C., STAB, F., WENCK, H., KOLBE, L., GRONNIGER, E. \& WINNEFELD, M. Genome-wide expression analysis of wounded skin reveals novel genes involved in angiogenesis. 2015, Angiogenesis, 18, 361-71.

9. AL-BEDHAWI, M. A. A. \& BICKNEL, A. Tmem121 A Novel Gene Associated With The Proliferation Activity of Adrenocortical Stem/ Progenitor Cells. 2019, Research Journal of Pharmaceutical, Biological and Chemical Sciences, 10,14 .

10. AL-BEDHAWI, M. A. A. Identification and characterisation of a potential adrenocortical stem cell population. university of Reading. 2018,

11. STAEDEL, C., HUA, Z., BROKER, T. R., CHOW, L. T., REMY, J.-S. \& BEHR, J.-P. High-Efficiency Transfection of Primary Human Keratinocytes with Positively Charged Lipopolyamine: DNA Complexes. 1994, Journal of Investigative Dermatology, 102, 768-772.

12. AROLA, J., HEIKKILA, P. \& KAHRI, A. I. Biphasic effect of ACTH on growth of rat adrenocortical cells in primary culture. 1993, Cell Tissue Res, 271, 169-76. 